\title{
Pertussis immunisation and control in England and Wales, 1957 to 2012: a historical review
}

G Amirthalingam (Gayatri.Amirthalingam@phe.gov.uk) ${ }^{1}$, S Gupta $^{1}$, H Campbell $^{1}$

1. Immunisation, Hepatitis and Blood Safety department, Public Health England, London, United Kingdom

Citation style for this article:

Amirthalingam G, Gupta S, Campbell H. Pertussis immunisation and control in England and Wales, 1957 to 2012: a historical review. Euro Surveill.

2013;18(38):pii=20587. Available online: http://www.eurosurveillance.org/ViewArticle.aspx?Articleld=20587

Article submitted on 19 September 2012 / published on 19 September 2013

This review summarises the epidemiology and control of pertussis in England and Wales since the introduction of routine immunisation and considers the implications for future control. Routine infant immunisation with a whole-cell pertussis (WP) vaccine was introduced in 1957 and had a marked impact on the overall disease burden. Following a fall in vaccine coverage during the 1970 s and 80 s linked to a safety scare with WP vaccine, there was an extended period of high coverage and pertussis incidence fell dramatically. Incidence continued to decrease with the introduction of an acellular pertussis vaccine in the pre-school booster in November 2001 and in the primary United Kingdom (UK) schedule in September 2004 but has increased since July 2011. In response to a high rate of pertussis in infants, a temporary vaccination programme for pregnant women was introduced in October 2012. The key aim of the programme is to protect vulnerable infants from birth in the first months of life, before they can be fully protected by routine infant immunisation. A review of the UK adolescent immunisation programme is currently ongoing and the inclusion of a pertussis booster is being considered.

\section{Introduction}

Pertussis (whooping cough) is an acute bacterial respiratory infection caused by Bordetella pertussis. It is characterised by a protracted coughing illness that can last for several weeks. The illness typically begins with a catarrhal stage followed by periods of intense paroxysmal coughing spells. Infants under 1 year are at the highest risk of complications, such as pneumonia and seizures, while adolescents and adults tend to display milder symptoms, sometimes without the classic features of a protracted paroxysmal cough.

Humans are the only known host for B. pertussis, so elimination through vaccination is theoretically possible. However, protection conferred by natural infection and current vaccination schedules is not lifelong [1]. Routine pertussis immunisation was introduced in England and Wales in 1957 with a whole-cell pertussis (wP) vaccine for infants from 3 months of age. In the pre-vaccine era, large epidemics of pertussis occurred every three to five years, affecting up to 150,000 people and contributing to approximately 300 deaths each year [2]. Although England and Wales have experienced an extended period of high vaccine coverage and disease incidence has fallen dramatically, pertussis remains the most common vaccine-preventable cause of hospitalisation and death in infants [3].

Pertussis persists as an infection of global public health importance. Many countries with long-standing vaccination programmes have reported a resurgence of pertussis, particularly in adolescents and adults [4-6] and young infants less than 6 months of age [7-9], despite sustained high vaccine coverage. This has led to a growing international debate on the potential strategies to optimise global pertussis control. A 2010 review by the Strategic Group of Experts in Immunisation (SAGE) on pertussis control strategies recommended a booster dose for children aged 1-6 years, preferably during the second year of life, following completion of the primary infant schedule [10]. Although a number of countries, including France, the United States (US) and Australia, have recommended adolescent boosters and cocooning (vaccinating close household contacts of young infants), data to support the introduction of neonatal pertussis immunisation remain inconclusive [10]. In 2011, the US became the first country to advise that pertussis-containing vaccine can be safely administered to pregnant women who have not previously received the recommended adult dose [11]. This advice was updated in October 2012 to recommend that pertussis-containing vaccine be routinely offered to women in every pregnancy [12].

Understanding the impact of different control strategies on pertussis epidemiology is likely to inform future vaccine policy in the UK and other countries. In this review, we present a historical overview of the epidemiology and control of pertussis in England and Wales in the pre- and post-vaccine era and the implications for future pertussis control. 
Annual notifications of pertussis (1940-2012, England and Wales) and vaccine coverage by the age of 2 years (1970-2012, England only)

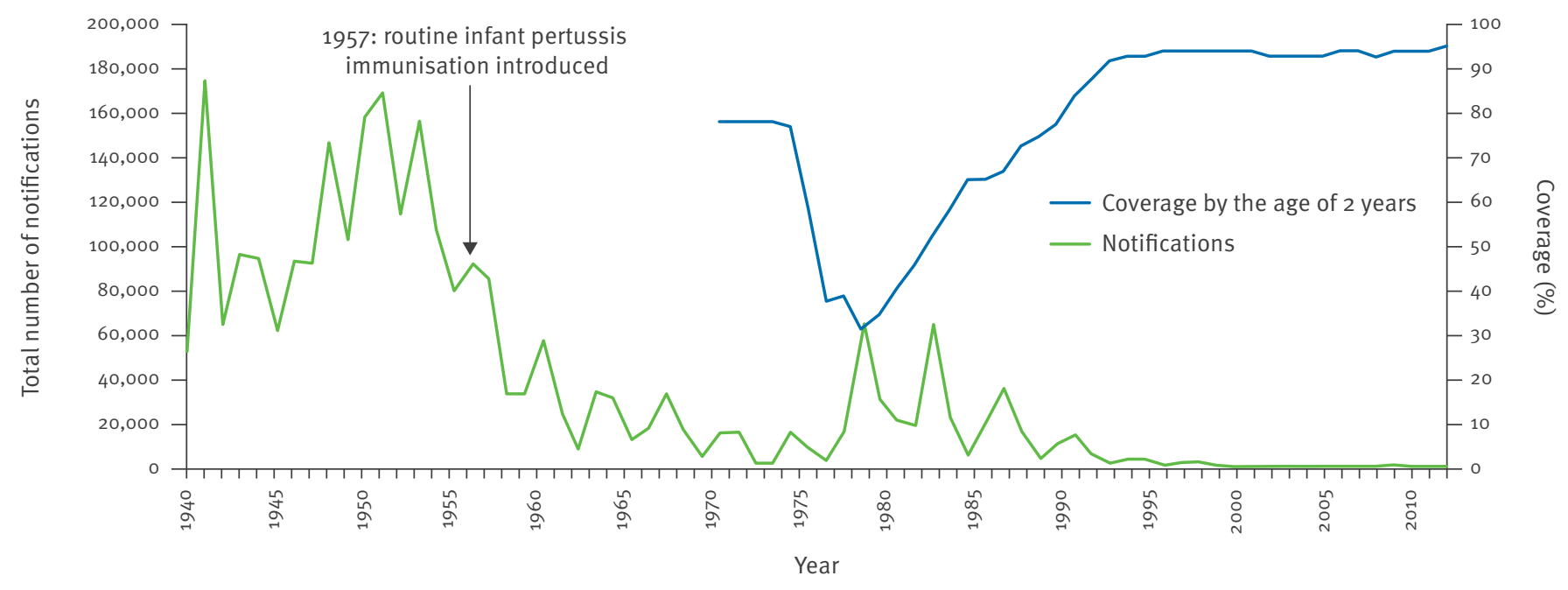

Source: [3], updated with data up to 2012.

\section{Methods}

Searches, not limited by language or country, were undertaken in November 2011 with the terms Bordetella pertussis, whooping cough, epidemiology and pertussis vaccine using the Cochrane Library, MEDLINE (1950-2011), the Cumulative Index to Nursing and Allied Health Literature (CINAHL) (1981-2011), Embase (1980-2011), the International Standard Randomised Controlled Trial Number (ISRCTN) Register, the Health Management Information Consortium database (a compilation of data from two sources, the UK Department of Health Library and Information Services and the King's Fund Information and Library Service) and from bibliographies of collected papers and reviews. An updated search was undertaken in September 2013, prior to publication, to identify any further relevant papers.

Grey literature and unpublished surveillance data from England and Wales were also identified and a number of key UK sites, including the Department of Health, Office for National Statistics and Health Protection Agency (now Public Health England), were accessed. Epidemiological data for England and Wales up to December 2012 were extracted. International websites were also searched, including those of the World Health Organization, the US Centers for Disease Control and Prevention and the Australian Department of Health and Ageing. All the abstracts or the full paper, if no abstract was available, were reviewed for relevance. Studies were included if any of the following criteria were met, based on a review of the full paper: epidemiological data on pertussis in England and Wales; pertussis vaccine trials and pertussis vaccine policy in England and Wales.

\section{Results}

\section{Literature search}

Around 650 articles were retrieved and each was designated to one of the three authors and the abstracts reviewed for relevance. When the abstract was not available, the full paper was obtained and assessed for a decision on its inclusion. Approximately 320 full papers were reviewed for inclusion. Following author review, 76 papers were retained for inclusion in the final review.

Development of the whole-cell vaccine and early vaccine trials (1913-1957)

The French researchers Bordet and Gengou described $B$. pertussis as the causative agent of whooping cough in 1906 [13]. By the 1920s, scientists had developed vaccines to control many infectious diseases including smallpox, typhoid fever, diphtheria and tetanus, but pertussis proved more challenging. By the 1930s, pertussis was an increasingly dominant cause of childhood mortality, outranking diphtheria, scarlet fever and measles in many European countries [14]. During the 1930s, the American researchers Kendrick and Eldering performed animal studies to design a potential candidate vaccine using inactivated whole $B$. pertussis bacilli [15-18]. In a field trial involving 1,592 (712 vaccinated and 880 control) children, there were 63 pertussis cases in the control group and only three in the vaccinated group [15]. North-American field trials of newer inactivated vaccines conducted in the 1940 s and 505 also demonstrated a protective effect $[15,19-21]$. As a result, the American medical community began to use the pertussis vaccine on an ad hoc basis [22]. 


\begin{tabular}{|c|c|c|c|c|c|c|c|c|c|}
\hline \multirow{3}{*}{ Years } & \multicolumn{3}{|c|}{ Incidence } & \multicolumn{3}{|c|}{ Case fatality } & \multicolumn{3}{|c|}{ Mortality } \\
\hline & \multicolumn{3}{|c|}{$\begin{array}{c}\text { Notifications } \\
\text { per } 1,000 \text { population }\end{array}$} & \multicolumn{3}{|c|}{$\begin{array}{c}\text { Deaths } \\
\text { per } 1,000 \text { notifications }\end{array}$} & \multicolumn{3}{|c|}{$\begin{array}{l}\text { Deaths } \\
\text { per million population }\end{array}$} \\
\hline & «1 year & $1-4$ years & 5-9 years & «1 year & $1-4$ years & $5-9$ years & «1 year & $1-4$ years & 5-9 years \\
\hline $1944-45$ & 12.1 & 17.7 & 8.4 & 65.7 & 6.99 & 1.05 & 796.3 & 123.6 & 8.8 \\
\hline $1946-49$ & 14.6 & 22.4 & 11.0 & 42.6 & 4.07 & 0.40 & 620.6 & 91.0 & $4 \cdot 4$ \\
\hline $1950-53$ & $19 \cdot 3$ & 28.2 & 15.0 & $15 \cdot 9$ & 1.24 & 0.12 & 307.7 & 35.1 & 1.8 \\
\hline $1954-57$ & 12.1 & 16.5 & 9.7 & 8.8 & 0.55 & 0.09 & 106.1 & 9.0 & 0.8 \\
\hline $1958-61$ & 5.0 & 6.1 & $4 \cdot 4$ & $5 \cdot 3$ & 0.46 & 0.07 & 26.5 & 2.8 & 0.3 \\
\hline $1962-65$ & 3.1 & $3 \cdot 5$ & 2.1 & 9.2 & 0.60 & 0.04 & 28.2 & 2.1 & 0.1 \\
\hline $1966-69$ & 2.3 & 3.0 & 1.6 & 8.7 & 0.13 & ND & 19.8 & 0.4 & ND \\
\hline $1970-73$ & 1.6 & 1.3 & 0.9 & 8.2 & 0.24 & 0.14 & 13.1 & 0.3 & 0.1 \\
\hline
\end{tabular}

ND: no deaths.

Source: [2].

Meanwhile, the vaccine was not widely accepted in the UK. The UK Medical Research Council (MRC) trials (1942-1944) had shown such vaccines to be ineffective [23] and the editor of the British Medical Journal cited these findings and argued that none of the American studies used proper control groups [24]. The Whooping Cough Immunisation Committee in the UK concluded that the vaccines used in the MRC trials differed in an undetermined way from those vaccines shown to offer protection in the American and Canadian studies [25] and so performed new field trials $[26,27]$ with a number of vaccines, including those of American origin used in previous studies.

In 1956, a review of two series of field studies was published in which 14 pertussis vaccines were tested for their effectiveness in 28,799 children [26]. The vaccines used in the first series of trials gave poor protection while those in the second series showed protection that was maintained for up to three years [28]. The latter series included three UK-manufactured vaccines using endemic strains of $B$. pertussis with comparable effectiveness to the reference vaccine made with American strains [26]. The studies highlighted the variability in the protection afforded by pertussis vaccines at that time. General and severe local reactions were rare.

While the field trials were in progress, vaccines were tested for their ability to protect mice against intra-cerebral pertussis infection [26]. A comparison between field and animal studies showed some correlation between the effectiveness in children and the ability to protect mice against intra-cerebral infection. The MRC trial concluded that only those vaccines with adequate efficacy, as demonstrated by the intra-cerebral mouseprotection test, should be issued for use in children [26].
Impact of routine wP vaccination in England and Wales Pertussis first became notifiable in England and Wales in 1940. The annual notifications due to pertussis (1940-2012) and vaccine coverage at 2 years of age (1970-2012) are shown in Figure 1. Despite an overall fall in notifications, a substantial increase in the number of cases was observed from 1948 to 1954. This might have partly been attributable to the post-war population 'boom' and increased public and professional awareness of pertussis, as a result of the MRC trials, resulting in more complete notification of clinical cases.

Following the introduction of routine pertussis immunisation with diphtheria, tetanus and whole-cell pertussis (DTwP) vaccine in the UK in 1957, there was a substantial decrease in notifications. Mortality associated with pertussis declined considerably after 1945 (Table) [2]. Before routine immunisation, this decline was observed in children aged under 10 years and so was likely to have been due to improved treatment, including widespread use of antibiotics [2]. Most pertussisrelated deaths occurred in infants (Table). Pertussis mortality rates fell further following the introduction of routine immunisation in 1957 (from 106.1 to 13.1 per million infants in 1954-57 and 1970-73, respectively) but case-fatality rates in infants remained relatively constant (5.3-9.2 deaths per 1,000 notifications) during the same period.

In a report published in 1977 , there was a consensus within the UK Joint Committee on Vaccination and Immunisation that the introduction of routine pertussis immunisation had been a major factor in the decrease of notified pertussis [2]. This reduction did not continue, however, and notifications stabilised during the 1960 s, with sustained 3-4 yearly cycles of increased incidence (Figure 1). The lack of a continued reduction 
in pertussis was considered likely to be due to either a change in the infecting bacterium or the use of vaccines with suboptimal effectiveness during 1957 to 1968 [2]. Moreover, considerable concern was raised by members of the committee, manufacturers, local health boards and general practitioners (GPs) regarding the risk of reactions attributable to the pertussis vaccine component. In 1964, the committee evaluated the benefits and risks and concluded that the pertussis vaccine had a protective effect [2]. However, ongoing concerns led to an investigation in 13 areas of Scotland, England and Wales and a Joint Committee on Vaccination and Immunisation report in 1968 revealed that of those children who developed pertussis, $55 \%$ were unvaccinated and $42 \%$ were vaccinated [29]. A 1969 Public Health Laboratory Service survey showed that vaccines used before 1968 were not very effective, with vaccine effectiveness of $20-30 \%$ [30]. Since 1968 , only vaccines with a potency of $\geq 4$ international units per dose have been marketed and this, together with the addition of aluminium hydroxide adjuvant, led to increased potency of the adsorbed vaccine [31].

Notifications reached a record low of just over 2,000 cases in 1972 (Figure 1). However, there was continuing debate about the impact of pertussis vaccination on disease burden, the risk of severe local and neurological reactions and difficulties with diagnosis, which culminated in a comprehensive review in 1977 [2]. This concluded that the effectiveness had been restored following changes to the vaccine's composition in line with the international potency standards and that a full course reduced both the risk and the severity of the disease.

wP vaccine safety scare in England and Wales (1970-1980s)

Before 1970, reviews of the pertussis vaccine were chiefly focused on its effectiveness. Concern regarding the reactogenicity of the pertussis component of the DTwP vaccine had been expressed for a number of years [32] and a causal relationship with neurological complications was suggested in 1974 [33], which led to a publicity campaign by groups seeking to highlight the hazards of vaccination. Media speculation on the safety of pertussis vaccine stimulated further parliamentary and public interest. In a House of Commons debate in 1974, it was stated that between 1,000 and 2,000 children in the UK had suffered irreversible brain damage as a result of the vaccine [32]. At that time, some publications also suggested that the introduction of mass vaccination had no effect on disease burden and had an association with neurological complications [34]. These findings were in contrast to those of Miller and Fletcher, who reported that the risk of an unvaccinated child being admitted to hospital with pertussis was eight times higher than that of a fully vaccinated child [35].

With sustained adverse publicity, the acceptance rate for pertussis immunisation in England fell from $79 \%$ in 1973 to $31 \%$ in 1978 (Figure 1) and the first of three national epidemics of pertussis occurred from 1977 to 1979 [36]. An estimated 5,000 hospital admissions, 200 cases of pneumonia, 83 cases of convulsions and 38 deaths occurred and the illness was often protracted and debilitating, lasting up to 10-12 weeks [23]. In comparison with previous epidemics, the attack rate in children aged under 5 years (in whom coverage was low) was considerably higher. The attack rate was especially high in areas where vaccination uptake was lowest [23].

In 1981, the National Childhood Encephalopathy Study (NCES), which aimed to provide an accurate estimate of the risk of neurological complications following pertussis immunisation, reported a preliminary risk estimate of approximately 1 in 310,000 (95\% confidence interval (Cl): 1 in 5,310,000 to 1 in 54,000) for a previously healthy child developing neurological sequelae persisting one year after immunisation [37]. However, a Joint Committee on Vaccination and Immunisation review in 1981 concluded that any risk from immunisation was low and outweighed by its advantages and that pertussis vaccine should continue to be recommended as part of the routine UK childhood immunisation programme [23].

An additional Public Health Laboratory Service study in 1982 [38] demonstrated that the vaccine was effective in preventing serious disease, which began to restore confidence in the vaccine. In 1988, the UK High Court ruled that a causal link between the vaccine and permanent brain damage had not been proven [39]. In 1993, the final report from the National Childhood Encephalopathy Study concluded that DTwP vaccine may, on rare occasions, be associated with the development of severe acute neurological illnesses that could have serious sequelae but concluded that the balance of the possible risks against the known benefits supported the continued use of the vaccine [40]. It was later shown that such cases can be due to Dravet syndrome, a rare genetic disorder that may initially present as a febrile seizure following immunisation [41].

A number of national initiatives were undertaken to improve overall vaccine coverage, including the establishment of District Immunisation Co-ordinator posts, the provision of financial incentives for GPs for achieving a target vaccine coverage [36] and the implementation of a national publicity campaign in 1985 [42]. Together with better public awareness of the disease and increasing confidence in the pertussis vaccine, these measures led to a sustained increase in coverage from 1980, which in 1988 reached levels of more than $75 \%$ for the first time (Figure 1).

\section{Accelerated schedule}

An accelerated 2-, 3- and 4-month primary infant schedule was introduced in England and Wales in June 1990 against a background of improving coverage. UK 
studies showed that an accelerated schedule provided satisfactory immunogenicity $[43,44]$ and lower levels of reactogenicity [45] than the previously recommended extended schedule (at 3, 4.5-5 and 8.5-11 months). The decision to recommend a 2-, 3- and 4-month rather than a 2-, 4- and 6-month schedule (as in the US), was based on a number of factors including the recognition that earlier completion of the schedule would afford more rapid protection against pertussis and be likely to improve vaccine coverage. Evidence based on clinic attendance rates suggested that attendance rates began to wane by the time a child reached $7-8$ months and thus the move to an accelerated schedule would increase the proportion of infants completing three doses [46]. This Joint Committee on Vaccination and Immunisation recommendation was also in part based on experience in Canada and the US, where schedules starting at the age of 2 months had been associated with a reduction in febrile convulsions [47].

It was later shown that completion of vaccination by the age of 4 months instead of 10 months may have resulted in a four-fold decrease in febrile convulsions attributable to the DTwP vaccine [48]. Despite the change to an accelerated schedule, a booster in the second year of life was not recommended in the UK. Assessment of antibody levels to diphtheria, tetanus and pertussis demonstrated adequate protection with an accelerated schedule (at the age of 3,4 and 5 months), which persisted to the age of the preschool booster [43].

For the first cohort of children immunised under the accelerated schedule, vaccine coverage at the age of 12 months was identical to that achieved at the age of 18 months on an extended immunisation schedule [49]. This suggested that the immediate impact of the new schedule was to reduce the average age at which children received the third dose. In addition to providing earlier protection, this accelerated schedule was expected to further increase coverage, as the dropout rate for the third dose was lower when scheduled earlier.

In the years following the introduction of the accelerated schedule (in 1990), public confidence in the wholecell vaccine continued to recover and coverage further increased for all vaccine antigens, including pertussis. Pertussis vaccine coverage by the age of 2 years reached $92 \%$ in 1992 and has since exceeded that level (Figure 1). Pertussis notifications in infants continued to fall from a peak of nearly 1,600 notifications in 1990. Peaks of pertussis disease in infants, however, continued to recur at lower levels every three to four years; the highest peak, between 1998 and 2009, was 300 notifications in infants in 2001 [3].

In addition to the overall reduction of disease in infants, the direct impact of the change to an accelerated schedule was apparent in the proportionate distribution of laboratory-confirmed cases in infants.
The proportion of cases in infants aged 6-11 months fell from $50 \%$ (1989) to $26 \%$ (2008), indicating earlier protection [3]. While there was a concurrent increase in the proportion of cases among infants aged under 3 months (from $17 \%$ in 1989 to $50 \%$ in 2008), incidence in this age group fell (from 134 per 100,000 in 1989 to 76 per 100,000 in 2008 ).

\section{Introduction of an acellular booster dose}

Data from the US in 1993 suggested that waning immunity among adults was becoming an important factor in maintaining disease transmission [50]. The pertussis epidemics in the UK in the 1970 s and 1980 s would have led to natural boosting in all age groups and it was therefore considered likely that disease transmission at older ages would be delayed for some years [51]. There was concern that early waning of immunity following an accelerated primary course could lead to inadequate immunity in the pre-school years and thus increase transmission to unimmunised young infants from older siblings [51]. However, early data in 1994 following the accelerated schedule did not support this concern $[42,52]$.

Whole-cell vaccine had been shown to have unacceptably high reactogenicity when given as a booster after a whole-cell primary course. Relative efficacy trials of highly purified acellular vaccines and whole-cell vaccines were under way in Sweden by the early 1990 s $[53,54]$. The potential role of acellular pertussis (aP) vaccines for boosting was recognised at that time. The Department of Health in England funded clinical trials to collect immunogenicity and reactogenicity data for the aP vaccine 2-, 3-, 4-month schedule and to generate data on its compatibility with other antigens in the UK schedule [55]. A Swedish multicentre trial of threeand five-component acellular vaccines and the wholecell vaccine in use in the UK confirmed that the latter was highly effective against mild and severe disease [56].

It had been suggested that the consistent three-to-fouryear intervals observed between peak years despite a reduction in incidence indicated that while WP vaccine provided good protection against clinical disease, it was poorly protective against transmission and provided a minimal herd-immunity effect [57]. Any change in disease incidence in infants aged under 3 months must be due to an indirect or herd effect as they are too young to be fully vaccinated. Miller and Gay showed how the epidemic period and the total number of notified cases in infants aged under 3 months up to 1994 fitted with a model that assumed $80 \%$ effectiveness against transmission, despite continued three-to-fouryearly cyclical increases in pertussis [58]. This modelling suggested that with sustained high coverage, even without the assumption of waning immunity, disease incidence was likely to increase in older children over 10 years of age and adults. 


\section{FIGURE 2}

Incidence of laboratory-confirmed pertussis by age group, England and Wales, 1998-2012

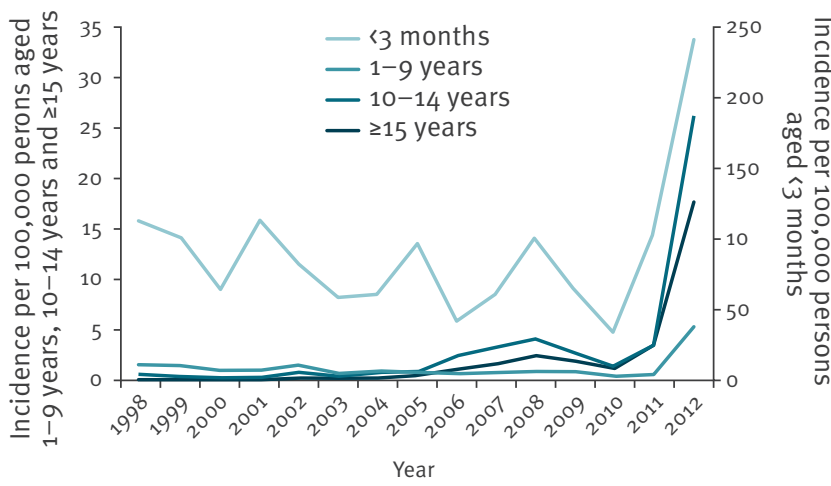

Source: Health Protection Agency.

In England and Wales, pertussis notifications from 1990 to 1997 continued to fall, with persistent peak levels of disease every three to four years [59]. While the number of cases in infants aged under 6 months fell overall in this period, the disproportionate pertussis burden in young infants, under-ascertainment of disease burden and the importance of household contacts as a source of infection helped inform the decision to introduce a pre-school pertussis booster. In 2000 , based on modelling by the Public Health Laboratory Service [60], the Joint Committee on Vaccination and Immunisation recommended that the most cost-effective introduction of a booster dose would be as an acellular pre-school booster, to indirectly protect infants too young to be immunised [61]. Whole-cell vaccine was not recommended due to its unacceptably high reactogenicity when used as a booster [62].

In November 2001, at a time of high vaccine coverage ( $94 \%$ at 2 years of age for completion of the primary course in England [63]), pertussis was introduced in the pre-school booster as a three- or five-component $\left(\mathrm{DTaP}_{3}\right.$ or $\left.\mathrm{DTaP}_{5}\right)$ vaccine given with oral polio vaccine (OPV) and measles-mumps-rubella vaccine. This further contributed to the continuing fall in the number of infant cases and an overall reduction in the incidence in children aged under 10 years from 1998 to 2009 (Figure 2) [3]. An initial estimate of the effectiveness of a four-dose schedule was $95.3 \%$ ( $95 \% \mathrm{Cl}: 91.9$ to 97.2 ), with cases followed up for up to seven years [3]. A fourdose schedule was estimated to provide an additional $46 \%$ ( $95 \% \mathrm{Cl}:-7$ to 71$)$ effectiveness compared with three doses [3].

\section{The incorporation of aP vaccines}

\section{into the primary schedule}

The Joint Committee on Vaccination and Immunisation agreed to move from wP to aP vaccines in the primary schedule when comparable efficacy was demonstrated [64], given the lower rates of systemic and local adverse reactions reported with aP vaccines, particularly in those eligible for the pre-school booster. Another consideration was that the DTwP vaccines contained thiomersal, a mercury-based preservative, while aP vaccines did not. Although there was (and still is) no evidence of harm, this decision was in line with an international aim to reduce children's mercury exposure from avoidable sources. The Joint Committee on Vaccination and Immunisation had previously agreed with the advice from the Committee on the Safety of Medicines to move to thiomersal-free vaccines when effective alternatives were available. The introduction of an aP primary course was also linked to the decision to replace OPV with inactivated polio vaccine (IPV) as soon as progress on global polio eradication reached a point where the risk of importation to the UK had fallen markedly [64]. Consideration of these issues led to the introduction of a combination vaccine including Haemophilus influenzae $b$ (Hib) (DTaP-Hib-IPV) into the primary UK schedule from September 2004, replacing the previous DTwP-Hib and OPV vaccines [65].

High primary coverage continued after the introduction of the DTaP-Hib-IPV vaccine (Figure 1) and, from July to September 2011, DTaP-Hib-IPV coverage by the age of 1 year in England was $94.4 \%$ and uptake for the pre-school DTaP-IPV vaccine was $85.4 \%$ by the age of 5 years [66]. The change in vaccine occurred during the observed fall in incidence in children aged under 10 years between 1998 and 2009 [3]. While notifications and laboratory-confirmed cases in those over 10 years increased over the same period (between 1998 and 2009), the incidence of hospitalised cases remained stable [3]. These increases in teenagers and adults were thought to have been influenced by the introduction of routine serology testing, leading to improved ascertainment in these age groups [3].

In 2011, the overall incidence of pertussis reached a similar level to that in 2008, the previous peak year [67]. The number of confirmed cases in people aged 15 years or older, however, exceeded expected levels and was nearly 50\% higher in 2011 than that in 2008 (incidence of 1.6 per 100,000 vs 1.1 per 100,000 ) [67]. While levels in younger age groups (including infants aged under 3 months) were also high, they were in line with anticipated cyclical increases (Figure 2). This rise in activity continued into the first half of 2012, with increases extending to young infants less than 3 months of age and led to a national outbreak being declared in April 2012 and the introduction of a temporary vaccination programme for pregnant women in October 2012 as an outbreak response measure $[68,69]$. Pertussis activity peaked in October 2012 and subsequently declined during 2013 across all age groups, in line with normal seasonal trends [70]. Although there has been a substantial fall in the number of cases among infants less than 3 months of age, this outbreak response measure remains in place while high levels of pertussis persist 
in those over 15 years of age and we approach the period between July to October where pertussis incidence is typically highest [70].

\section{Discussion}

The introduction of routine pertussis immunisation has had a marked impact on the burden of pertussis in England and Wales. The change to an accelerated schedule and sustained high vaccine coverage further reduced pertussis incidence. Since the inclusion of pertussis vaccine in the pre-school booster, there has been a continued reduction in pertussis incidence in children aged 3 months to 9 years. Pertussis incidence is still highest in infants aged under 3 months who cannot be fully protected by immunisation and who are most likely to suffer serious complications. The key aim of the pertussis immunisation programme is to protect these vulnerable infants.

Since the routine availability of serology testing from 2002 , the increase in the reported incidence in people aged 10 years and above has been attributed to improved case ascertainment. The recent disproportionate increase in older age groups, however, appears to be a true rise, particularly in those aged 15-40 years. This follows similar increases seen in other countries including Australia, the US and the Netherlands [4,71-73] and is in line with the predictions of Miller and Gay [58]. Although this increase has arisen after the transition to the routine use of the aP vaccine, the age groups affected largely fall outside the aP cohorts (both booster and routine). Vaccine uptake was $78 \%$ in 1971 , falling to $31 \%$ by 1978 then recovering to $92 \%$ by 1992. Cohorts born in this period therefore had a lower likelihood of vaccine protection but a greater chance of natural exposure. As pertussis activity fell to consistently lower levels after 1990, boosting through natural exposure was unlikely in all age groups from 1991 to 2010.

The Strategic Group of Experts in Immunisation review concluded in 2010 that the introduction of an adolescent booster should be based on cost-effectiveness [10]. In those countries where adolescent boosters have been introduced (US and Australia), a decreased pertussis burden in the target population has been reported but the impact on the disease in infants is uncertain. Data from the US [74] do not show indirect benefits but the Australian data suggested some benefit for infants when using a school-based catch-up programme (with a broad age group) and a routine programme targeting adolescents aged 12 years and older [75]. A Joint Committee on Vaccination and Immunisation review of the UK adolescent programme is ongoing and inclusion of the pertussis vaccine is being considered. Given the level of under-ascertainment from routine surveillance, accurate estimates of pertussis incidence and burden in adolescents will be essential to inform future costeffectiveness analyses.
In response to the ongoing national outbreak and the high rates of disease in infants, a temporary vaccination programme for pregnant women was launched in the UK on 1 October $2012[68,69]$. This outbreak response measure was introduced following a review by the Joint Committee on Vaccination and Immunisation of potential vaccine strategies to optimise protection for young infants before their primary course can be delivered [76]. Assessment of the impact and effectiveness of this strategy are curren

\section{Acknowledgements}

The authors would like to thank Sanofi Pasteur MSD for an unrestricted educational grant to Health Protection Agency (since April 2013, Public Health England). The company had no role in the opinions expressed in or the content and writing of the manuscript. The authors would also like to thank Kazim Beebejaum for his assistance in obtaining copies of the references. 


\section{References}

1. Wendelboe AM, Van Rie A, Salmaso S, Englund JA. Duration of immunity against pertussis after natural infection or vaccination. Pediatr Infect Dis J. 2005;24(5 Suppl):S58-61. http://dx.doi.org/10.1097/01.inf.0000160914.59160.41. PMid:15876927.

2. Joint Committee on Vaccination and Immunisation (JCVI). Report on the Review of the Evidence on Whooping Cough Vaccination. 1977. Kew, London: The National Archives, D/ W43/6 Vol A.

3. Campbell H, Amirthalingam G, Andrews N, Fry NK, George RC, Harrison TG, et al. Accelerating control of pertussis in England and Wales. Emerg Infect Dis. 2012;18(1):38-47. http://dx.doi.org/10.3201/eid1801.110784. PMid:22260989. PMCid:PMC3381681.

4. Quinn HE, McIntyre PB. Pertussis epidemiology in Australia over the decade 1995-2005 - trends by region and age group. Commun Dis Intell Q Rep. 2007;31(2):205-15. PMid:17724997.

5. Skowronski DM, De Serres G, MacDonald D, Wu W, Shaw C, Macnabb J, et al. The changing age and seasonal profile of pertussis in Canada. J Infect Dis. 2002;185(10):1448-53. http:// dx.doi.org/10.1086/340280. PMid:11992280.

6. Tan T, Trindade E, Skowronski D. Epidemiology of pertussis. Pediatr Infect Dis J. 2005;24(5 Suppl):S10-8. http://dx.doi. org/10.1097/01.inf.0000160708.43944.99. PMid:15876918.

7. Tanaka M, Vitek CR, Pascual FB, Bisgard KM, Tate JE, Murphy TV. Trends in pertussis among infants in the United States, 1980-1999. JAMA. 2003;290(22):2968-75. http://dx.doi. org/10.1001/jama.290.22.2968. PMid:14665658.

8. Somerville RL, Grant CC, Scragg RK, Thomas MG Hospitalisations due to pertussis in New Zealand in the preimmunisation and mass immunisation eras. J Paediatr Child Health. 2007;43(3):147-53. http://dx.doi.org/10.1111/j.14401754.2007.01034.x. PMid:17316188.

9. Spokes PJ, Quinn HE, McAnulty JM. Review of the 2008-2009 pertussis epidemic in NSW: notifications and hospitalisations. N S W Public Health Bull. 2010;21(7-8):167-73. http://dx.doi. org/10.1071/NB10031. PMid:20883655.

10. Pertussis vaccines: WHO position paper. Wkly Epidemiol Rec. 2010;85(40):385-400. PMid:20939150.

11. Centers for Disease Control and Prevention (CDC). Updated recommendations for use of tetanus toxoid, reduced diphtheria toxoid and acellular pertussis (Tdap) vaccine from the Advisory Committee on Immunization Practices, 2010. MMWR Morb Mortal Wkly Rep. 2011;60(1):13-5. PMid:21228763.

12. Centers for Disease Control and Prevention (CDC). Updated recommendations for use of tetanus toxoid, reduced diphtheria toxoid, and acellular pertussis vaccine (Tdap) in pregnant women--Advisory Committee on Immunization Practices (ACIP), 2012. MMWR Morb Mortal Wkly Rep. 2013;62(7):131-5. PMid:23425962.

13. Bordet J, Gengou O. Le microbe de la coqueluche. [The microbe of pertussis]. Ann Inst Pasteur (Paris). 1906;20:731-41. French.

14. Jefferson T. Why the MRC randomized trials of whooping cough (pertussis) vaccines remain important more than half a century after they were done. J R Soc Med. 2007;100(7):3435. http://dx.doi.org/10.1258/jrsm.100.7.343. PMid:17606757 PMCid:PMC1905874.

15. Shapiro-Shapin CG. Pearl Kendrick, Grace Eldering, and the pertussis vaccine. Emerg Infect Dis. 2010;16(8):1273-8. http://dx.doi.org/10.3201/eid1608.100288. PMid:20678322. PMCid:PMC3298325.

16. Kendrick P, Eldering G. A study in active immunization against pertussis. Am J Hygiene. 1939;29(Sec B):133-53.

17. Kendrick P, Eldering G. Progress report on pertussis immunization. Am J Public Health Nations Health. 1936;26(1):812. http://dx.doi.org/10.2105/AJPH.26.1.8

18. Kendrick PL. Pearl L. Kendrick papers 1888-1979. Ann Arbor, MI: Michigan Historical Collections, Bentley Historical Library, University of Michigan. Available from: http://quod.lib.umich. edu/cgi/f/findaid/findaid-idx?cc=bhlead;c=bhlead;idno=umi ch-bhl-85242;didno=umich-bhl-85242;rgn=main;view=text

19. Kendrick PL. Use of alum-treated pertussis vaccine, and of alum-precipitated combined pertussis vaccine and diphtheria toxoid, for active immunization. Am J Public Health Nations Health. 1942;32(6):615-26. http://dx.doi.org/10.2105/ AJPH.32.6.615. PMid:18015628. PMCid:PMC1526873.

20. Bell JA. Diphtheria immunization; use of an alum-precipitated mixture of pertussis vaccine and diphtheria toxoid. I Am Med Assoc. 1948;137(12):1009-16. http://dx.doi.org/10.1001/ jama.1948.02890460005002. PMid:18871856.

21. Bell JA. Pertussis immunization; use of two doses of an alum-precipitated mixture of diphtheria toxoid and pertussis vaccine. J Am Med Assoc. 1948;137(15):1276-81. http://dx.doi. org/10.1001/jama.1948.02890490004002. PMid:18870019.

22. Felton HM, Willard CY. Current status of prophylaxis by Hemophilus pertussis vaccine. Report of the Council on Pharmacy and Chemistry of the American Medical Association. J Am Med Assoc. 1944;126:294-9. http://dx.doi.org/10.1001/ jama.1944.82850400002008

23. Committee on Safety of Medicines (CSM), the Joint Committee on Vaccination and Immunisation (JCVI) and Department of Health and Social Security (DHSS). Whooping cough: reports from the Committee on Safety of Medicines and the Joint Committee on Vaccination and Immunisation. London: Her Majesty's Stationery Office (HMSO); 1981.

24. Vaccination against Whooping-cough. Br Med J. 1945;2(4415):222-3. http://dx.doi.org/10.1136/bmj.2.4415.222

25. McFarlan AM, Topley E, Fisher M. Trial of whoopingcough vaccine. Br Med J. 1945;2(4415):205-8. http:// dx.doi.org/10.1136/bmj.2.4415.205. PMid:20786225. PMCid:PMC2059601.

26. Vaccination against whooping-cough; relation between protection in children and results of laboratory tests; a report to the Whooping-cough Immunization Committee of the Medical Research Council and to the medical officers of health for Cardiff, Leeds, Leyton, Manchester, Middlesex, Oxford, Poole, Tottenham, Walthamstow, and Wembley. Br Med J. 1956;2(4990):454-62. http://dx.doi.org/10.1136/ bmj.2.4990.454. PMid:13342513. PMCid:PMC 2034830.

27. Prevention of whooping-cough by vaccination; a Medical Research Council investigation. Br Med J. 1951;1(4721):1463-71. http://dx.doi.org/10.1136/bmj.1.4721.1463

28. Doull JA, Shibley GS, Haskin GE, Bancroft H, McClelland JE, Hoelscher $\mathrm{H}$. Active immunization against pertussis: final report on the Cleveland immunizations of 1934-1935. Am J Dis Child. 1939;58(4):691-8.

29. Joint Committee on Vaccination and Immunisation. Minutes of meeting held on Monday, 11th November, 1968. London: Department of Health; 1968. Available from: http://webarchive. nationalarchives.gov.uk/20130107105354/http://www.dh.gov. uk/prod_consum_dh/groups/dh_digitalassets/@dh/@ab/ documents/digitalasset/dh_117620.pdf

30. Efficacy of whooping-cough vaccines used in the United Kingdom before 1968. A preliminary report to the Director of the Public Health Laboratory service by the Public Health Laboratory Service Whooping-Cough Committee and Working Party. Br Med J. 1969;4(5679):329-33. http:// dx.doi.org/10.1136/bmj.4.5679.329. PMid:4318320. PMCid:PMC1629570.

31. Joint Committee on Vaccination and Immunisation Minutes of meeting held on 5 th November 1969, London: Department of Health; 1969. [Accessed 19 Sep 2013]. Available from: http:// webarchive.nationalarchives.gov.uk/20120907090205/http:// www.dh.gov.uk/prod consum_dh/groups/dh_digitalassets/@ dh/@ab/documents/digitalasset/dh_117623.pdf

32. Joint Committee on Vaccination and Immunisation. Minutes of meeting held on 30 April 1974. London: Department of Health; 1974. Available from: http://webarchive.nationalarchives.gov. uk/20130107105354/http://www.dh.gov.uk/prod_consum_dh/ groups/dh_digitalassets/@dh/@ab/documents/digitalasset/ dh_117597.pdf

33. Kulenkampff M, Schwartzman JS, Wilson J. Neurological complications of pertussis inoculation. Arch Dis Child. 1974;49(1):46-9. http://dx.doi.org/10.1136/adc.49.1.46. PMid:4818092. PMCid:PMC1648839.

34. Stewart GT. Vaccination against whooping-cough. Efficacy versus risks. Lancet. 1977;1(8005):234-7. http://dx.doi. org/10.1016/S0140-6736(77)91028-5

35. Miller CL, Fletcher WB. Severity of notified whooping cough. Br Med J. 1976;1(6002):117-9. http://dx.doi.org/10.1136/ bmj.1.6002.117

36. Gangarosa EJ, Galazka AM, Wolfe CR, Phillips LM, Gangarosa RE, Miller E, et al. Impact of anti-vaccine movements on pertussis control: the untold story. Lancet. 1998;351(9099):356-61. http://dx.doi.org/10.1016/ S0140-6736(97)04334-1

37. Miller DL, Ross EM, Alderslade R, Bellman MH, Rawson NS. Pertussis immunisation and serious acute neurological illness in children. Br Med J (Clin Res Ed). 1981;282(6276):1595-9. http://dx.doi.org/10.1136/bmj.282.6276.1595

38. Miller DL, Alderslade R, Ross EM. Whooping cough and whooping cough vaccine: the risks and benefits debate. Epidemiol Rev. 1982;4:1-24. PMid:6128242.

39. Griffith $\mathrm{AH}$. Permanent brain damage and pertussis vaccination: is the end of the saga in sight? Vaccine. 1989;7(3):199-210 http://dx.doi. org/10.1016/0264-410X(89)90229-6 
40. Miller D, Madge N, Diamond J, Wadsworth J, Ross E. Pertussis immunisation and serious acute neurological illnesses in children. BMJ. 1993;307(6913):1171-6. http://dx.doi.org/10.1136/bmj.307.6913.1171. PMid:7504540. PMCid:PMC1679309.

41. Mclntosh AM, McMahon J, Dibbens LM, Iona X, Mulley JC, Scheffer IE, et al. Effects of vaccination on onset and outcome of Dravet syndrome: a retrospective study. Lancet Neurol. 2010;9(6):592-8. http://dx.doi.org/10.1016/ S1474-4422(10)70107-1

42. White JM, Fairley CK, Owen D, Matthews RC, Miller E. The effect of an accelerated immunisation schedule on pertussis in England and Wales. Commun Dis Rep CDR Rev. 1996;6(6):R8691. PMid:8664929.

43. Ramsay ME, Rao M, Begg NT, Redhead K, Attwell AM. Antibody response to accelerated immunisation with diphtheria, tetanus, pertussis vaccine. Lancet. 1993;342(8865):203-5. http://dx.doi.org/10.1016/0140-6736(93)92298-8

44. Ramsay ME, Corbel MJ, Redhead K, Ashworth LA, Begg NT. Persistence of antibody after accelerated immunisation with diphtheria/tetanus/pertussis vaccine. BMJ. 1991;302(6791):1489-91. http://dx.doi.org/10.1136/ bmj.302.6791.1489

45. Ramsay ME, Rao M, Begg NT. Symptoms after accelerated immunisation. BMJ. 1992;304(6841):1534-6. http:// dx.doi.org/10.1136/bmj.304.6841.1534. PMid:1628051. PMCid:PMC1882405.

46. Jones AE, Johns A, Magrath DI, Melville-Smith M, Sheffield F. Durability of immunity to diphtheria, tetanus and poliomyelitis after a three dose immunization schedule completed in the first eight months of life. Vaccine. 1989;7(4):300-2. http://dx.doi.org/10.1016/0264-410X(89)90189-8

47. Joint Committee on Vaccination and Immunisation. Minutes of the meeting held on Friday 3 November 1989 in room 83/84 Hannibal House at $10.30 \mathrm{am}$. London: Department of Health; 1989. Available from: http://webarchive.nationalarchives.gov. uk/20130107105354/http://www.dh.gov.uk/prod_consum_dh/ groups/dh_digitalassets/@dh/@ab/documents/digitalasset/ dh_095205.pdf

48. Farrington P, Pugh S, Colville A, Flower A, Nash J, MorganCapner P, et al. A new method for active surveillance of adverse events from diphtheria/tetanus/pertussis and measles/ mumps/rubella vaccines. Lancet. 1995;345(8949):567-9. http:// dx.doi.org/10.1016/S0140-6736(95)90471-9

49. White JM, Hobday S, Begg NT. 'COVER' (cover of vaccination evaluated rapidly): 19. CDR (Lond Engl Rev). 1991;1(12):R140.

50. Resurgence of pertussis. 1993. Wkly Epidemiol Rec. 1994;69(13):95-8. PMid:8193014.

51. Miller E, Vurdien JE, White JM. The epidemiology of pertussis in England and Wales. Commun Dis Rep CDR Rev. 1992;2(13):R1524. PMid:1285134.

52. Miller E, White JM, Fairley CK. Pertussis vaccination. Lancet. 1994;344(8936):1575-6. http://dx.doi.org/10.1016/ So140-6736(94)90385-9

53. Hallander HO, Gustafsson L. Efficacy and effectiveness of acellular pertussis vaccines: a 20-year Swedish experience. Expert Rev Vaccines. 2009;8(10):1303-7. http://dx.doi. org/10.1586/erv.09.88. PMid:19803750.

54. Gustafsson L, Hallander HO, Olin P, Reizenstein E, Storsaeter J. A controlled trial of a two-component acellular, a fivecomponent acellular, and a whole-cell pertussis vaccine. $\mathrm{N}$ Engl J Med. 1996;334(6):349-55. http://dx.doi.org/10.1056/ NEJM199602083340602. PMid:8538705.

55. Miller E. Public health implications: United Kingdom. Dev Biol Stand. 1997;89:367-8. PMid:9272373.

56. Whooping cough vaccine trial compares British whole cell vaccine and acellular vaccines. Commun Dis Rep CDR Wkly. 1997;7(21):181. PMid:9505458.

57. Fine PE, Clarkson JA. The recurrence of whooping cough: possible implications for assessment of vaccine efficacy. Lancet. 1982;1(8273):666-9. http://dx.doi.org/10.1016/ S0140-6736(82)92214-0

58. Miller E, Gay NJ. Epidemiological determinants of pertussis. Dev Biol Stand. 1997;89:15-23. PMid:9272331.

59. Van Buynder PG, Owen D, Vurdien JE, Andrews NJ, Matthews RC, Miller E. Bordetella pertussis surveillance in England and Wales: 1995-7. Epidemiol Infect. 1999;123(3):403-11. http:// dx.doi.org/10.1017/S0950268899003052. PMid:10694150. PMCid:PMC 2810773.

6o. Edmunds WJ, Brisson M, Melegaro A, Gay NJ. The potential cost-effectiveness of acellular pertussis booster vaccination in England and Wales. Vaccine. 2002;20(9-10):1316-30. http:// dx.doi.org/10.1016/S0264-410X(01)00473-X

61. Joint Committee on Vaccination and Immunisation. Minutes of the meeting held on Monday 9 October 2000. London:
Department of Health; 2000. Available from: http:// webarchive.nationalarchives.gov.uk/20130107105354/http:// www.dh.gov.uk/prod_consum_dh/groups/dh_digitalassets/@ dh/@ab/documents/digitalasset/dh_117402.pdf

62. Joint Committee on Vaccination and Immunisation. Minutes of the meeting held on Friday 4 May 2001. London: Department of Health; 2001. Available from: http://webarchive. nationalarchives.gov.uk/20130107105354/http://www.dh.gov. uk/prod_consum_dh/groups/dh_digitalassets/@dh/@ab/ documents/digitalasset/dh_117380.pdf

63. NHS immunisation statistics, England 2000-01. London: Department of Health; Sep 2001. Available from: http:// webarchive.nationalarchives.gov.uk/20130107105354/http:// www.dh.gov.uk/prod_consum_dh/groups/dh_digitalassets/@ $\mathrm{dh} / @ e n / d o c u m e n t s /$ digitalasset/dh_4022636.pdf

64. Joint Committee on Vaccination and Immunisation. Minutes of the meeting held on 6 February 2004. London: Department of Health; 2004. Available from: http://webarchive. nationalarchives.gov.uk/20130107105354/http://www.dh.gov. uk/prod_consum_dh/groups/dh_digitalassets/@dh/@ab/ documents/digitalasset/dh_095072.pdf

65. Department of Health (DH). New vaccinations for the childhood immunisation programme. London: DH; 10 Aug 2004. Available from: http://webarchive.nationalarchives.gov. uk/20130107105354/http://www.dh.gov.uk/prod_consum_dh/ groups/dh_digitalassets/@dh/@en/documents/digitalasset/ dh_4087347.pdf

66. Health Protection Agency (HPA). Quarterly vaccination coverage statistics for children aged up to five years in the UK (COVER programme): July to September 2011. Health protection report. 2011;5(50). London: HPA; 16 Dec 2011. Available from: http://www.hpa.org.uk/hpr/archives/2011/hpr5011.pdf

67. Health Protection Agency (HPA). Laboratory-confirmed cases of pertussis reported to the enhanced pertussis surveillance programme (England and Wales): Quarterly reports for July-September and October-December 2011; Annual report for 2011. Health protection report. 2012;6(8). London: HPA; 24 Feb 2012. Available from: http://www.hpa.org.uk/hpr/ archives/2012/hpro812.pdf

68. Amirthalingam G. Strategies to control pertussis in infants. Arch Dis Child. 2013;98(7):552-5. http://dx.doi.org/10.1136/ archdischild-2012-302968. PMid:23698594.

69. Department of Health (DH). Pregnant women to be offered whooping cough vaccination. London: $\mathrm{DH} ; 28$ Sep 2012. News story. Available from: http://www.dh.gov.uk/health/2012/09/ whooping-cough/

70. Public Health England (PHE). Laboratory confirmed cases of pertussis reported to the enhanced pertussis surveillance programme (England): April - June 2013. Health protection report. 7(34). London: PHE; 23 Aug 2013 Available from: http:// www.hpa.org.uk/hpr/archives/2013/hpr3413.pdf

71. Campbell P, McIntyre P, Quinn H, Hueston L, Gilbert GL, McVernon J. Increased population prevalence of low pertussis toxin antibody levels in youngchildren preceding a record pertussis epidemic in Australia. PLoS One. 2012;7(4):e35874. http://dx.doi.org/10.1371/journal.pone.0035874. PMid:22558249. PMCid:PMC3338806.

72. Centers for Disease Control and Prevention (CDC). Pertussis epidemic--Washington, 2012. MMWR Morb Mortal Wkly Rep. 2012 Jul 20;61(28):517-22. PMid:22810264.

73. van der Maas NA, Mooi FR, de Greeff SC, Berbers GA, Spaendonck MA, de Melker HE. Pertussis in the Netherlands, is the current vaccination strategy sufficient to reduce disease burden in young infants? Vaccine. 2013. pii: So264-410X(13)01046-3.

74. Skoff TH, Cohn AC, Clark TA, Messonnier NE, Martin SW. Early impact of the US Tdap vaccination program on pertussis trends. Arch Pediatr Adolesc Med. 2012;166(4):344-9. http:// dx.doi.org/10.1001/archpediatrics.2011.1093. PMid:22213608.

75. Quinn HE, Mclntyre PB. The impact of adolescent pertussis immunization, 2004 2009: lessons from Australia. Bull World Health Organ. 2011 Sep 1;89(9):666-74.

76. Joint Committee on Vaccination and Immunisation (JCVI). Minutes of the meeting held on Thursday 3oth August 2012 and post teleconference discussion. London: Department of Health; 2012. Available from: https://www.gov.uk/government/ uploads/system/uploads/attachment_data/file/223497/JCVI_ minutes_Aug_2012_Pertussis_-_final.pdf 